\title{
Homocysteine during the third trimester is a risk factor for preeclampsia: A prospective study
}

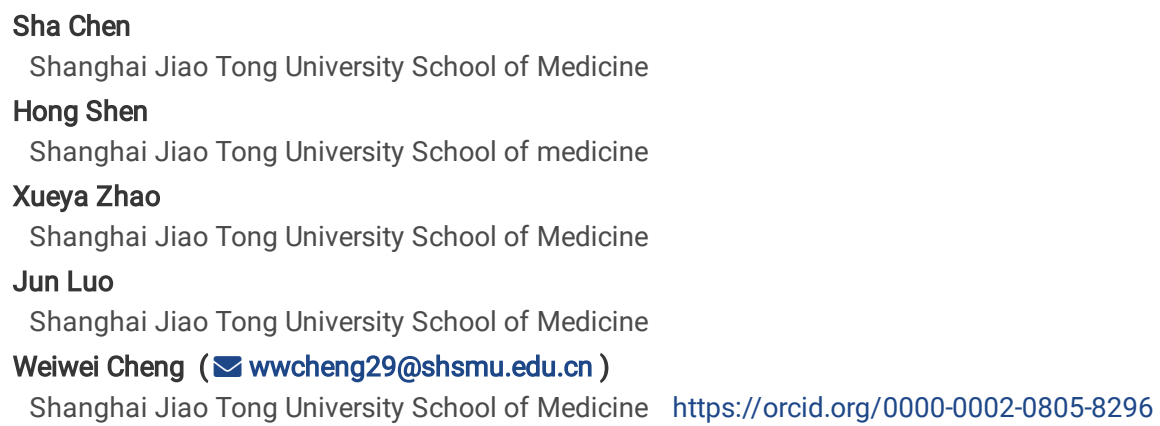




\section{Abstract}

Background: The purpose of this study was to investigate the risk factors for elevating homocysteine during pregnancy and the relative effects on preeclampsia, so as to further understand whether Hcy had predictive value for PE.

Method: This is a prospective study that only covers pregnant women with singleton who received regular prenatal care from July to September 2018 exclusively at IPMCH (N=1142). Homocysteine, folic acid and vitamin B12 were tested in the $1^{\text {st }}$ trimester $\left(10-14\right.$ weeks), $2^{\text {nd }}$ trimester $\left(24-28\right.$ weeks), and $3^{\text {rd }}$ trimester (30-34 weeks), respectively, and MTHFR genes (rs1801133, rs1801131, rs17367504) were detected. Therefore, the analysis of this case includes the variation in Hcy levels during pregnancy, risk factors for elevating homocysteine and the risk factors on preeclampsia.

Results: (1) Homocysteine was lowest in the $1^{\text {st }}$ trimester. (2) Homocysteine was negatively correlated with folic acid ( $\left.\mathrm{r}=-0.17, p<0.001\right)$ and vitamin $\mathrm{B} 12$ $(r=-0.15, p<0.001)$ in the same trimester. (3) Both of heterozygous CT $(p=0.025,95 \% \mathrm{Cl} 0.018,0.275)$ and homozygous TT ( $p<0.001,95 \% \mathrm{Cl} 0.185,0.501)$ in MTHFR rs1801133 might be risk factors that caused an increase in Hcy. G-spot mutations in MTHFR rs17367504 might be a risk factor that caused a decline in homocysteine. (4) Homocysteine in the $3^{\text {rd }}$ trimester might be significantly correlated with increasing risk of preeclampsia $(\mathrm{OR}=1.2,95 \% \mathrm{Cl} 1.01,1.42)$, particularly early-onset preeclampsia $(\mathrm{OR}=3.63,95 \% \mathrm{Cl} 1.71,7.71)$ and severe preeclampsia $(\mathrm{OR}=3.63,95 \% \mathrm{Cl} 1.71,7.71)$.

Conclusions: The variation in homocysteine level in the third trimester might be associated with preeclampsia, especially early-onset preeclampsia and severe preeclampsia, and MTHFR, folic acid and vitamin B12 might be the three critical factors responsible for the changing homocysteine levels during pregnancy.

\section{Background}

Preeclampsia (PE) is a pregnancy-specific disease that occurs after 20 weeks of gestation and manifests as hypertension and proteinuria with or without visceral damage. The incidence of PE is 3-5\%[1], which reasonably accounts for the increased maternal and prenatal morbidity and mortality.

Previous studies have suggested that PE may be associated with elevated homocysteine (Hcy) during pregnancy. Hcy is a sulfur-containing amino acid intermediate in the metabolism of methionine and cysteine. Cotter[2] has found that Hcy is significantly higher in PE than in normal pregnancies, especially in the $1^{\text {st }}$ trimester, which in turn increases the risk of severe PE. However, Hietala[3] found no significant differences in gestational Hcy between the PE group and the normal pregnancy group. The role of Hcy remains controversial. Therefore, this study identifies the changes in Hcy during pregnancy, risk factors for hyper homocysteine (H-Hcy) and effects of gestational Hcy on PE.

\section{Methods}

\section{Participant}

Single pregnant women who received regular prenatal care at the International Peace Maternal and Child Health Hospital (IPMCH) affiliated with Shanghai Jiao Tong University School of Medicine from July 2018 to September 2018 were selected and they all taken folic acid or multivitamins (containing folic acid) during pregnancy. The exclusion criteria were as follows: (1) twin or multiple pregnancy; (2) pre-pregnancy with hypertension, diabetes, kidney disease, severe anemia and other internal and surgical diseases; (3) use of aspirin or other drugs during pregnancy; and (4) non-Han pregnancy. A total of 1142 participants were enrolled in this study. After the pregnant women were enrolled in the $1^{\text {st }}$ trimester (10-14 weeks), they were followed up when the need antenatal care and blood samples were collected in the $1^{\text {st }}$ trimester (10-14 weeks), the $2^{\text {nd }}$ trimester (24-28 weeks), and the $3^{\text {rd }}$ trimester (30-34 weeks) when they have to do regular blood test during pregnancy. The follow-up was completed until 6 weeks postpartum or withdraw. General data, blood biochemical results and pregnancy outcomes of the subjects were collected. The diagnostic criteria for PE were based on American College of Obstetricians and Gynecologists (ACOG) guidelines (2019) for gestational hypertension and PE.[4] All participants provided written informed consent.

\section{Method}

According to the above inclusion and exclusion criteria, a total of 1142 pregnant women were included in this study. Levels of Hcy, FA and vitamin B12 were detected in the $1^{\text {st }}$ trimester (10-14 weeks), $2^{\text {nd }}$ trimester (24-28 weeks), and $3^{\text {rd }}$ trimester (30-34 weeks), and MTHFR genes (rs1801133, rs1801131, rs17367504) were also detected. At the same time, clinical information of the enrolled pregnant women was collected, including general information, test results and pregnant outcomes.

Blood sampling

Samples of venous blood (4 ml) were collected in the first trimester (10-14 weeks), second trimester (24 to 28 weeks), and third trimester (30-34 weeks). Two milliliters of blood were placed in the tube containing inert separation of coagulant, and the upper serum was taken for Hcy, folic acid and vitamin B12 detection after centrifugation. The other $2 \mathrm{ml}$ of blood was placed in a tube containing EDTA anticoagulant, and the lower blood cells were collected for DNA extraction after centrifugation to detect the MTHFR gene.

\section{Biochemical analyses}

In this study, the cyclic enzymatic method was used to detect Hcy (Wuhan Hi-tech Medical Devices Park, Wuhan, China) with Roche reagent (Cabas8000 automatic biochemical analyzer, Roche Ltd., Shanghai, China). Folic acid (Daoyuan Biological Technology Ltd., Shanghai, China) and vitamin B12 (Daoyuan Biological Technology Ltd., Shanghai, China) were detected by chemiluminescence (ARCHITECT i2000, Abbott, Shanghai, China), and the Abbott ARCHITECT i2000 biochemical analysis system was used. 
MTHFR gene detection

DNA was extracted according to the instructions of the genomic DNA extraction kit (Tiangen Biochemical Technology Co., Ltd, Shanghai, China). MTHFR rs1801133, MTHFR rs1801131 and MTHFR rs17367504 were selected, and PCR primers were designed and synthesized using Primer 7.0 software (LightCycler480 Software, Roche Ltd., Shanghai, China). The primers were as follows: (1) MTHFR rs1801133: 5'-GCTGACCTGAAGCACTTGAAG-3', 5'CAAAGCGGAAGAATGTGTCA-3'; (2) MTHFR rs1801131: 5'-AGAGCAAGTCCCCAGAGG-3', 5'-CCCGAGAGGTAAAGAACGAA-3'; (3) MTHFR rs17367504: 5'ACCCATTGAAGAGTGTGTCTAAAA-3', 5'-AAGGAGAAGGCAGAGTGGGT-3'. PCR amplification procedures were set as follows: pre-denaturation at $94^{\circ} \mathrm{C}$ for 3 minutes, denaturation at $94^{\circ} \mathrm{C}$ for 5 seconds, annealing at $60^{\circ} \mathrm{C}$ for 30 seconds, and extension at $60^{\circ} \mathrm{C}$ for 30 seconds for 40 cycles. The products were identified by DNA agarose gel electrophoresis.

\section{Statistical analyses}

R 3.5.3 software (Mathsoft, USA) was used for statistical analysis. For demographic description, continuous variables were described by the mean \pm SD and quartile spacing, and classification variables were described by the proportion of each subgroup.

For continuous variables, first, according to the single factor linear model, the initial screening was used to identify the risk factors related to Hcy, folic acid and vitamin B12 ( $p \leq 0.1)$, the optimal multiple linear model (AIC minimum) was determined based on the backward elimination method (AIC minimum), and then VIF $<2$ was taken as the standard to determine whether collinearity existed between variables. Background factors related to Hcy, folic acid and vitamin B12 were analyzed according to the determined multiple linear model $(P<0.05)$. The Mauchly sphericity test determines whether the variance in the difference between different measurements is equal when repeated measurements are made. According to the random intercept model, the changes in Hcy, folic acid and vitamin B12 levels in different periods of pregnancy were analyzed, and the curves of Hcy, folic acid and vitamin B12 levels in different periods of pregnancy were drawn in the form of the mean \pm standard deviation.

According to pregnancy outcome, for the classified variable, the optimal multiple linear model (AIC minimum) was determined based on the backward elimination method based on the initial screening of influencing factors related to outcome $(P \leq 0.1)$ in the univariate logistic regression model, and collinearity among variables was judged based on $\mathrm{VIF}<2$. The regression model was used to analyze the influencing factors related to pregnancy outcome ( $p<0.05)$. The statistical tests were all double-sided, and the confidence interval was $95 \%$ reliable.

\section{Results}

Baseline characteristics

Demographic description was compared using mean \pm SD and the proportion of each subgroup (Table1). A total of 1142 participants, with an average age of $31.29 \pm 3.96$ years and a pre-gestational BMI of $21.16 \pm 2.75 \mathrm{~kg} / \mathrm{m}^{2}$ was selected for this study. Three MTHFR genes were detected as follows: (1) MTHFR rs1801133: 366 cases with CC type (32.05\%), 529 cases with CT type (46.32\%), and 247 cases with TT type (21.63\%). The T mutation rate was $67.95 \%$. (2) MTHFR rs $1801131: 752$ cases with AA type (65.85\%), 356 cases with AC type (31.17\%), and 34 cases with CC type (2.98\%). The C mutation rate was $18.56 \%$. (3) MTHFR rs17367504: 950 cases with AA type (83.19\%), 183 cases with AG type (16.02\%), and 9 cases with GG type (0.79\%). The G mutation rate was $8.80 \%$ (Table 1).

Changes in Hcy during pregnancy

Hcy levels in different trimester were compared using paired t test. Hcy was the lowest in the first trimester compared with the second and third trimesters $(p<0.001)$, but the participants appeared to have no significant differences between the second and third trimesters (Figure 2 and Table 2 ).

Risk factors for Hcy

Pearson correlation coefficient $r$ was used to determine the correlation between Hcy and FA, vitamin B12 in the same period. Hcy during pregnancy was negatively correlated with folic acid $(r=-0.17, p<0.001)$ and vitamin B12 $(r=-0.15, p<0.001)$ in the same period (Table 3), and Hcy increased with the decrease in folic acid and vitamin B12. We used single factor linear model and multiple linear model to analyze the risk factors of Hcy. Along with the gradual decrease in folic acid and vitamin B12 during pregnancy, Hcy increased as gestational weeks increased (Figure 2).

MTHFR rs 1801133 had a significant effect on Hcy during pregnancy, and heterozygous CT $(p=0.025,95 \% \mathrm{Cl} 0.018,0.275)$ and homozygous TT ( $p<0.001,95 \%$ $\mathrm{Cl} 0.185,0.501)$ both caused an increase in Hcy. However, the impact of homozygous TT was stronger than that of heterozygous CT, and G-spot mutations in MTHFR rs17367504 have protective effects on Hcy, which may cause Hcy to decline during pregnancy (Table 4).

This study also points out that a history of PE was a risk factor for increasing Hcy during pregnancy $(p=0.011,95 \% \mathrm{Cl} 0.326,2.478)$. Hcy increased significantly, while creatinine $(p<0.001,95 \% \mathrm{Cl} 0.030,0.049)$, albumin $(p<0.001,95 \% \mathrm{Cl} 0.067,0.118)$ and globulin $(p=0.001,95 \% \mathrm{Cl} 0.012,0.049)$ increased, and low-density lipoprotein decreased $(p=0.016,95 \% \mathrm{Cl} 0.211,0.022)$ (Table 4$)$.

Impact of Hcy on PE

The regression model was used to analyze the influencing factors related to PE (Table5). The rise in Hcy levels in the third trimester significantly increased the risk of $\mathrm{PE}(\mathrm{OR}=1.2,95 \% \mathrm{Cl} 1.01,1.42)$, particularly early-onset $\mathrm{PE}(\mathrm{OR}=3.63,95 \% \mathrm{Cl} 1.71,7.71)$ and severe $\mathrm{PE}(\mathrm{OR}=3.63,95 \% \mathrm{Cl} 1.71,7.71)$, but there is no correlation between elevating Hcy and late-onset PE $(p>0.05)$. Hcy levels in the first trimester and PE had no significant correlation. We also found that the three MTHFR genes referred to in this study had no significant correlation with the risk of PE.

Page $3 / 10$ 


\section{Discussion}

We conducted a prospective study that focused on the changes in Hcy during pregnancy, risk factors for Hcy and the impacts of Hcy on PE because there were controversies about Hcy, MTHFR genes and PE.

Changes in Hcy

The average value for Hcy in the subjects in this study was $4.36 \pm 1.05 \mu \mathrm{mol} / \mathrm{L}$ in the first trimester $(10-14$ weeks), $5.95 \pm 1.46 \mu \mathrm{mol} / \mathrm{L}$ in the second trimester (24-28 weeks), and 5.95 $\pm 1.74 \mu \mathrm{mol} / \mathrm{L}$ in the third trimester (30-34 weeks). Hcy in the second and third trimesters was significantly higher than that in the first trimester, similar to the results of Rolf[5] and MW Wallace[6], which may be due to physiological changes and endocrine hormone changes during pregnancy such as HCG. Boxmeer[7] found that after HCG administration, Hcy level had been significantly lower than before during the menstrual cycle. This research found that pregnancy folic acid and vitamin B12 gradually decrease with increasing gestational age, which could explain the changes in Hcy during pregnancy.

Mark Walker[8] found that Hcy drops in the second trimester and then rises in the third trimester, which is different from the results of this study, and the possible reasons are as follows: (1) The detection of gestational weeks selected by the study is different. Gestational weeks chosen by Mark Walker to detect Hcy were 8-16 weeks, 20-28 weeks and 36-42 weeks. (2) Different methods were used in the study. Mark Walker selected pregnant women at different gestational weeks during the same period for the test, while this study conducted a prospective longitudinal study of the changes in the same population at different periods. (3) Due to the different times of the study, the living standards and nutrition intake of the people in 2019 changed greatly compared with those in 1999, which could lead to different results of the two studies. (4) Based on the Chinese population's perception of the timing of multivitamin (containing folic acid) supplementation, some pregnant women take multivitamins before conception and in the first trimester and quit for the second and third trimesters, which could explain why Hcy in this study was significantly higher in the second and third trimesters. After adjusting for risk factors affecting folic acid and vitamin B12, we found that Hcy, folic acid and vitamin B12 were negatively correlated in the first ( $r=-0.17$ for FA, $r=-0.15$ for Vitamin B12), second $(r=-0.17$ for FA, $r=-0.06$ for Vitamin B12) and third trimesters ( $r=-0.25$ for FA, $r=-0.11$ for Vitamin B12) $(p<0.05)$. With an increase in gestational age, folic acid and vitamin B12 decreased significantly in the second and third trimesters of pregnancy, along with increasing Hcy levels, further indicating the possible reasons for the changes in Hcy during pregnancy in this study.

In this study, MTHFR was found that it might be another factor causing the increase in Hcy, and the mutation rate of the MTHFR gene involved in this study was similar to the results of Moll[9] and Wu. X[10]. Mutations in the MTHFR gene can significantly weaken the function of tetrahydrofolate reductase, and the activity of tetrahydrofolate reductase of heterozygous MTHFR rs 1801133 can be reduced to $65 \%$ of that of normal people, while the activity of homozygous individuals is only $30 \%[9]$. The enzyme activity of homozygous MTHFR rs 1801131 was $60 \%$ of normal[9]. Therefore, mutations in the MTHFR gene might be one of the risk factors affecting Hcy in pregnancy[11], which was similar to result in this study. At the same time, we also found that the G mutation of MTHFR rs17367504 had had a protective effect on Hcy during pregnancy, and the G mutation might cause Hcy decline. This might explain Thomsen's findings[12]. Thomsen[12] first found that the $\mathrm{G}$ mutation at MTHFR rs 17367504 was a protective factor for PE (OR=0.65, 95\% Cl 0.53-0.80). In addition to the MTHFR gene, creatinine and protein levels in pregnancy were also possible factors that influence Hcy in pregnancy. The reason might be that the increase in creatinine affects the metabolism of Hcy and reduces urine excretion, which further causes the increase in Hcy in blood[11].

Impact of Hcy on PE

At present, there have been many studies on the correlation among Hcy, MTHFR genes and PE, and the findings are controversial. One study found that the Hcy of the T mutants at MTHFR rs1801133 was significantly higher than that of the non-mutants[13], which further increases the risk of the occurrence of PE[14]. Sunkara[15] found that in the PE group, the T mutation rate of MTHFR rs1801133 was significantly higher than that in the normal group. Furthermore, Dickerson[16] found that the T mutation of MTHFR rs1801133 was not significantly correlated with PE. There was no significant correlation among the three MTHFR genes referred to in this study and the risk of PE (including early-onset PE and severe PE) ( $p>0.05)$. Therefore, this study indicates that there is no direct correlation between the MTHFR genes and PE, and mutations in the MTHFR gene are risk factors for elevating Hcy during pregnancy which might directly or indirectly lead to vascular endothelial dysfunction, oxidative stress response, stimulate vascular smooth muscle cell proliferation, disrupt the body's coagulation and fibrinolytic system, and ultimately increase the risk of PE[17].

This study found that elevating Hcy might be correlated with the risk of $\mathrm{PE}$ in the third trimester ( $\mathrm{OR}=1.2,95 \% \mathrm{Cl} 1.01,1.42)$, especially in early-onset $\mathrm{PE}$ $(\mathrm{OR}=3.63,95 \% \mathrm{Cl} 1.71,7.71, p=0.001)$ and severe $\mathrm{PE}(\mathrm{OR}=1.46,95 \% \mathrm{Cl} 1.21,1,76, p<0.001)$, but not late-onset $\mathrm{PE}(\mathrm{p}>0.05)$. There was no correlation between Hcy in the first trimester and PE ( $p>0.05)$. However, most researchers believe that Hcy in the PE group was significantly higher than that in normal pregnancies, and the increasing Hcy level, especially in the first trimester, significantly increases the risk of PE, which is different from the results of this study[2,18-20]. In the Finnish study, Hietala[3] found no significant differences in Hcy between the PE group and normal group. Such differences may be due to different gestational weeks detecting Hcy. Kahn[21] has found that Hcy detection at 22-26 weeks of gestation showed no significant difference between the PE group and the normal group, while Hogg[22] found that the same group, with no difference at 26 weeks, had a significant difference in Hcy detection at 37 weeks. This is similar to the results of this study, and the possible reasons for such differences are as follows: (1) The gestational weeks detected in this study were 10-14 weeks, 24-28 weeks, and 30-34 weeks, and it can be inferred that Hcy before 28 gestational weeks had no significant correlation with PE. The detection of Hcy at 30-34 gestational weeks was significantly associated with PE, especially early-onset PE and severe PE. (2) The sample size of this study is limited, and the number of cases of PE is small, which is not enough to reflect the predictive value of Hcy in the first trimester for PE. (3) The detection results of Hcy are greatly affected by blood lipids[23], which are prone to increase during pregnancy, especially for patients with PE who usually have abnormal lipid metabolism[24,25], and it may have a certain influence on the detection results. (4) This study find that Hcy in the third trimester was more significantly correlated with early-onset PE, possibly because its detection of gestational weeks were very similar to the onset of the disease, or the test samples were collected at the onset of early-onset preeclampsia. (5) This study find that Hcy in the third trimester was correlated with early-onset PE, other than late-onset 
$\mathrm{PE}$, possibly due to the different pathogenesis between early-onset PE and late-onset PE. Early-onset PE arises owing to defective placentation which is similar to the pathogenesis mechanism of adverse pregnancy outcomes caused by elevated Hcy, whilst late-onset PE may center around interactions between normal senescence of the placenta and a maternal genetic predisposition to cardiovascular and metabolic disease.[26] Therefore, although the correlation between Hcy in the third trimester and PE is statistically significant, further studies are necessary to confirm whether Hcy can be used as an early indicator of clinical disease.

Strengths and limitation

One of the main strengths of this study is that this was a prospective study by testing the same patient at different gestational ages. We analyzed the correlation between Hcy levels in the first and third trimester of the same patient who finally progressed to PE and took MTHFR genes variation into account.

The limitation of this study regards assessments of folic acid supplementation dose, gestational age, and dietary intake of folate and vitamin B12. Because the dietary structure and living habits of the included subjects are quite different and the use of multivitamins during pregnancy is not the same throughout the gestational period, it is difficult to conduct a quantitative study on the intake of folic acid and vitamin B12 during pregnancy, but a maternal blood test was taken to measure folic acid and vitamin B12 levels instead. On the other hand, the sample size of this study is limited, and the number of cases of PE is small, which is not enough to reflect the predictive value of Hcy in the first trimester for PE.

\section{Conclusions}

In this study, the correlation between Hcy and PE is discussed in detail, and Hcy in pregnancy is lowest in the first trimester and increases with increasing gestational age. MTHFR, folic acid and vitamin B12 might be the most critical factors for changing Hcy in pregnancy. Hcy level in the third trimester might be associated with $\mathrm{PE}$, especially early-onset $\mathrm{PE}$ and severe $\mathrm{PE}$, rather than that in the first trimester.

\section{Declarations}

\section{Ethics approval and consent to participate:}

The study was approved by the Ethics Committee of the International Peace Maternity and Child Health Hospital, Shanghai Jiaotong University, Shanghai, China. (GKLW2017-102) All participants has given written informed consent.

\section{Consent for publication}

Not applicable

\section{Availability of data and materials}

The datasets used and/or analyzed during the current study are available from the corresponding author on reasonable request.

\section{Competing interests:}

There is no conflict of interest in relation to this article.

\section{Funding details:}

This research was supported by the Shanghai Municipal Commission of Health and Family Planning (20174Y0051), Major Disease Project of Xuhui district Municipal Health Planning Committee (XHLHGG201805)

\section{Author's contributions:}

SC: Project development, Data Collection, Manuscript writing

HS: Data Collection, Manuscript writing

$\mathrm{XYZ}$ : Data analysis

$\mathrm{JL}:$ Biochemical test

WWC: Project development, Data management, Manuscript editing

All authors have approved the final version of the manuscript.

\section{Acknowledgements:}

Not applicable

\section{References}


1. Ananth CV, Keyes KM, Wapner RJ (2013) Pre-eclampsia rates in the United States, 1980-2010: age-period-cohort analysis. BMJ : British Medical Journal 347 (nov07 15):f6564-f6564. doi:10.1136/bmj.f6564

2. Cotter AM, Molloy AM, Scott JM, Daly SF (2001) Elevated plasma homocysteine in early pregnancy: a risk factor for the development of severe preeclampsia. American journal of obstetrics and gynecology 185 (4):781-785. doi:10.1067/mob.2001.117304

3. Hietala R TU, Laatikainen T. (2001) Serum Homocysteine at 16 Weeks and Subsequent Preeclampsia. Obstet Gynecol 97 (4):527-529

4. ACOG Practice Bulletin No. 202: Gestational Hypertension and Preeclampsia (2019 Jan). Obstet Gynecol 133 (1):e1-e25

5. Cikot RJ S-TR, Thomas CM, de Boo TM, Merkus HM, Steegers EA. (2001) Longitudinal vitamin and homocysteine levels in normal pregnancy. Br J Nutr 85 (1):49-58

6. Julie MW Wallace MPB, JJ Strain,etc (2008) Homocysteine concentration, related B vitamins, and betaine in pregnant women recruited to the Seychelles Child Development Study. The American Journal of Clinical Nutrition 87 (2):391-397

7. Boxmeer JC, Steegers-Theunissen RP, Lindemans J, Wildhagen MF, Martini E, Steegers EA, Macklon NS (2008) Homocysteine metabolism in the preovulatory follicle during ovarian stimulation. Human Reproduction (Oxford, England) 23 (11):2570-2576. doi:10.1093/humrep/den292

8. M C W (1999) Changes in homocysteine levels during normal pregnancy. American journal of obstetrics and gynecology 3 Pt 1 (180)

9. Moll S, Varga EA (2015) Homocysteine and MTHFR Mutations. Circulation 132 (1):e6-9. doi:10.1161/CIRCULATIONAHA.114.013311

10. Wu X, Yang K, Tang X, Sa Y, Zhou R, Liu J, Luo Y, Tang W (2015) Folate metabolism gene polymorphisms MTHFR C677T and A1298C and risk for preeclampsia: a meta-analysis. Journal of Assisted Reproduction and Genetics 32 (5):797-805. doi:10.1007/s10815-014-0408-8

11. Zaric BL, Obradovic M, Bajic V, Haidara MA, Jovanovic M, Isenovic ER (2019) Homocysteine and Hyperhomocysteinaemia. Current medicinal chemistry 26 (16):2948-2961. doi:10.2174/0929867325666180313105949

12. Thomsen LCV, McCarthy NS, Melton PE, Cadby G, Austgulen R, Nygård OK, Johnson MP, Brennecke S, Moses EK, Bjørge L, Iversen AC (2017) The antihypertensive MTHFR gene polymorphism rs17367504-G is a possible novel protective locus for preeclampsia. Journal of Hypertension 35 (1):132139. doi:10.1097/hjh.0000000000001131

13. Mislanova C, Martsenyuk O, Huppertz B, Obolenskaya M (2011) Placental markers of folate-related metabolism in preeclampsia. Reproduction (Cambridge, England) 142 (3):467-476. doi:10.1530/REP-10-0484

14. al. KMe (1999) Correction: Increased Frequency of Genetic Thrombophilia in Women with Complications of Pregnancy. The New England journal of medicine 341 (5):384-384. doi:10.1056/nejm199907293410524

15. Sunkara SK, Khairy M, El-Toukhy T, Khalaf Y, Coomarasamy A (2010) The effect of intramural fibroids without uterine cavity involvement on the outcome of IVF treatment: a systematic review and meta-analysis. Human Reproduction (Oxford, England) 25 (2):418-429. doi:10.1093/humrep/dep396

16. Dickerson EH, Cho LW, Maguiness SD, Killick SL, Robinson J, Atkin SL (2010) Insulin resistance and free androgen index correlate with the outcome of controlled ovarian hyperstimulation in non-PCOS women undergoing IVF. Human Reproduction (Oxford, England) 25 (2):504-509.

doi:10.1093/humrep/dep393

17. Stamler JS, Slivka A (1996) Biological chemistry of thiols in the vasculature and in vascular-related disease. Nutrition Reviews 54 (1 Pt 1):1-30. doi:10.1111/j.1753-4887.1996.tb03770.x

18. Onalan R, Onalan G, Gunenc Z, Karabulut E (2006) Combining 2nd-trimester maternal serum homocysteine levels and uterine artery Doppler for prediction of preeclampsia and isolated intrauterine growth restriction. Gynecol Obstet Invest 61 (3):142-148

19. Gris JC, Perneger TV, Quere I, Mercier E, Fabbro-Peray P, Lavigne-Lissalde G, Hoffet M, Dechaud H, Boyer JC, Ripart-Neveu S, Tailland ML, Daures JP, Mares P, Dauzat M (2003) Antiphospholipid/antiprotein antibodies, hemostasis-related autoantibodies, and plasma homocysteine as risk factors for a first early pregnancy loss: a matched case-control study. Blood 102 (10):3504-3513. doi:10.1182/blood-2003-01-0320

20. Sorensen TK, Malinow MR, Williams MA, King IB, Luthy DA (1999) Elevated second-trimester serum homocyst(e)ine levels and subsequent risk of preeclampsia. Gynecol Obstet Invest 48 (2):98-103

21. Kahn SR, Platt R, McNamara H, Rozen R, Chen MF, Genest J, Jr., Goulet L, Lydon J, Seguin L, Dassa C, Masse A, Asselin G, Benjamin A, Miner L, Ghanem A, Kramer MS (2009) Inherited thrombophilia and preeclampsia within a multicenter cohort: the Montreal Preeclampsia Study. Am J Obstet Gynecol 200 (2):151.e151-159; discussion e151-155.

22. Hogg BB, Tamura T, Johnston KE, Dubard MB, Goldenberg RL (2000) Second-trimester plasma homocysteine levels and pregnancy-induced hypertension, preeclampsia, and intrauterine growth restriction. American journal of obstetrics and gynecology 183 (4):805-809. doi:10.1067/mob.2000.109044

23. Obeid R, Herrmann W (2009) Homocysteine and lipids: S-adenosyl methionine as a key intermediate. FEBS letters 583 (8):1215-1225. doi:10.1016/j.febslet.2009.03.038

24. Spracklen CN, Smith CJ, Saftlas AF, Robinson JG, Ryckman KK (2014) Maternal hyperlipidemia and the risk of preeclampsia: a meta-analysis. American journal of epidemiology 180 (4):346-358. doi:10.1093/aje/kwu145

25. Chavan-Gautam P, Rani A, Freeman DJ (2018) Distribution of Fatty Acids and Lipids During Pregnancy. Advances in clinical chemistry 84:209-239. doi:10.1016/bs.acc.2017.12.006

26. Burton GJ, Redman CW, Roberts JM, Moffett A (2019) Pre-eclampsia: pathophysiology and clinical implications. BMJ : British Medical Journal 366:I2381. doi:10.1136/bmj.I2381

\section{Tables}

Table 1 Demographic information and other baseline characteristics 


\begin{tabular}{|c|c|c|c|c|}
\hline & $\mathrm{N}$ & Proportion (\%) & Mean \pm SD & Median (IQR) \\
\hline Age & 1142 & & $31.29 \pm 3.96$ & $31[28,34]$ \\
\hline Education & 1142 & & & \\
\hline Primary School & 1 & 0.09 & & \\
\hline Junior School & 22 & 1.93 & & \\
\hline Senior School & 69 & 6.04 & & \\
\hline Bachelor & 801 & 70.14 & & \\
\hline Master & 221 & 19.35 & & \\
\hline Doctor & 28 & 2.45 & & \\
\hline Gravity & 1142 & & $0.79 \pm 1.03$ & $0[0,1]$ \\
\hline Parity & 1142 & & $0.29 \pm 0.48$ & $0[0,1]$ \\
\hline \multicolumn{5}{|c|}{ History of spontaneous abortion/missed abortion } \\
\hline No & 985 & 86.25 & & \\
\hline Yes & 157 & 13.75 & & \\
\hline \multicolumn{5}{|l|}{ History of Preeclampsia } \\
\hline No & 1139 & 99.74 & & \\
\hline Yes & 3 & 0.26 & & \\
\hline \multicolumn{5}{|l|}{ History of FGR } \\
\hline No & 1141 & 99.91 & & \\
\hline Yes & 1 & 0.09 & & \\
\hline \multicolumn{5}{|l|}{ Cigarette } \\
\hline No & 1135 & 99.39 & & \\
\hline Yes & 7 & 0.61 & & \\
\hline \multicolumn{5}{|l|}{ Alcohol } \\
\hline No & 1121 & 98.16 & & \\
\hline Yes & 21 & 1.84 & & \\
\hline \multicolumn{5}{|l|}{ Fertilization } \\
\hline Natural conception & 1016 & 88.97 & & \\
\hline Ovulation Induction & 14 & 1.23 & & \\
\hline IUI & 3 & 0.26 & & \\
\hline IVF-ET & 109 & 9.54 & & \\
\hline Prenatal BMI $\left(\mathrm{Kg} / \mathrm{m}^{2}\right)$ & & & $21.16 \pm 2.75$ & $20.70[19.20,22.58]$ \\
\hline \multicolumn{5}{|l|}{$\mathrm{BP}$ in $1^{\text {st }}$ trimester } \\
\hline $\mathrm{SBP}(\mathrm{mmHg})$ & & & $109.6 \pm 11.73$ & $110[102,118]$ \\
\hline $\mathrm{DBP}(\mathrm{mmHg})$ & & & $68.97 \pm 9.03$ & $69[63,75]$ \\
\hline \multicolumn{5}{|l|}{$1^{\text {st }}$ trimester } \\
\hline Creatinine $(\mu \mathrm{mol} / \mathrm{L})$ & & & $49.05 \pm 6.17$ & $49[45,53]$ \\
\hline $\operatorname{Albumin}(\mathrm{g} / \mathrm{L})$ & & & $41.93 \pm 2.16$ & $41.90[40.50,43.38]$ \\
\hline Globulin(g/L) & & & $29.03 \pm 3.04$ & $29.00[27.00,30.90]$ \\
\hline $\mathrm{TG}(\mathrm{mmol} / \mathrm{L})$ & & & $1.39 \pm 0.55$ & $1.27[1.00,1.64]$ \\
\hline $\mathrm{TC}(\mathrm{mmol} / \mathrm{L})$ & & & $4.38 \pm 0.82$ & $4.33[3.89,4.85]$ \\
\hline $\mathrm{HDL}(\mathrm{mmol} / \mathrm{L})$ & & & $1.86 \pm 0.38$ & $1.84[1.62,2.10]$ \\
\hline $\mathrm{LDL}(\mathrm{mmol} / \mathrm{L})$ & & & $2.42 \pm 0.62$ & $2.36[2.00,2.78]$ \\
\hline \multicolumn{5}{|l|}{ MTHFR rs1801133 } \\
\hline $\mathrm{CC}$ & 366 & 32.05 & & \\
\hline $\mathrm{CT}$ & 529 & 46.32 & & \\
\hline $\mathrm{TT}$ & 247 & 21.63 & & \\
\hline \multicolumn{5}{|l|}{ MTHFR rs1801131 } \\
\hline AA & 752 & 65.85 & & \\
\hline $\mathrm{AC}$ & 356 & 31.17 & & \\
\hline $\mathrm{CC}$ & 34 & 2.98 & & \\
\hline \multicolumn{5}{|l|}{ MTHFR rs17367504 } \\
\hline AA & 950 & 83.19 & & \\
\hline AG & 183 & 16.02 & & \\
\hline GG & 9 & 0.79 & & \\
\hline \multicolumn{5}{|l|}{$\mathrm{PE}$} \\
\hline No & 1108 & 97.02 & & \\
\hline Yes & 34 & 2.98 & & \\
\hline \multicolumn{5}{|l|}{ Early-onset PE } \\
\hline No & 1136 & 99.47 & & \\
\hline Yes & 6 & 0.53 & & \\
\hline Severe PE & & & & \\
\hline
\end{tabular}


* FGR: fetal growth restriction; IUI: intra-uterine insemination; BP: blood pressure; SBP: systolic blood pressure; DBP: diastolic blood pressure; TG: Triglyceride; TC: Total cholesterol; HDL: high density lipoprotein; LDL: low density lipoprotein; GW: gestational week; PE: preeclampsia;

Table2 Level of Hcy, FA and Vit B12 during different gestation stages

\begin{tabular}{lcccc}
\hline & $1^{\text {st }}$ trimester & $2^{\text {nd }}$ trimester & $3^{\text {rd }}$ trimester & $p$-value \\
\hline Hcy $(\mu \mathrm{mol} / \mathrm{L})$ & $4.36 \pm 1.05^{+}$ & $5.95 \pm 1.46^{*}$ & $5.95 \pm 1.74^{*}$ & $<0.001$ \\
FA $(\mu \mathrm{mol} / \mathrm{L})$ & $33.64 \pm 7.09^{+}$ & $28.53 \pm 13.46^{*}$ & $28.72 \pm 16.43^{*}$ & $<0.001$ \\
Vit B12 $(\mu \mathrm{mol} / \mathrm{L})$ & $384.98 \pm 152.92^{+}$ & $290.71 \pm 13.46^{*}$ & $290.71 \pm 13.46^{*}$ & $<0.001$ \\
$\mathrm{GW}(\mathrm{W})$ & $12.36 \pm 0.48$ & $24.91 \pm 0.84$ & $32.93 \pm 2.14$ & $<0.001$ \\
\hline
\end{tabular}

*Compared with $1^{\text {st }}$ trimester: $p<0.05$ is considered statistically; ${ }^{+}$Compared with $2^{\text {nd }}$ trimester: $p<0.05$ is considered statistically; GW: gestational week;

Table3 Pearson correlation coefficient between HCY and FA and Vit B12 during pregnancy

\begin{tabular}{lcccc}
\hline & & Hcy in $1^{\text {st }}$ trimester $(p)$ & Hcy in $2^{\text {nd }}$ trimester $(p)$ & Hcy in $3^{\text {rd }} \operatorname{trimester}(p)$ \\
\hline $1^{\text {st }}$ trimester & FA & $-0.17(<0.001)^{*}$ & & \\
& Vit B12 & $-0.15(<0.001)^{*}$ & & \\
\cline { 2 - 5 } $2^{\text {nd }}$ trimester & FA & & $-0.17(<0.001)^{*}$ & \\
& Vit B12 & $-0.06(0.03)^{*}$ & \\
\hline \multirow{2}{*}{$3^{\text {rd }}$ trimester } & FA & & & $-0.25(<0.001)^{*}$ \\
\cline { 2 - 4 } & Vit B12 & & $-0.11(<0.001)^{*}$ \\
\hline
\end{tabular}

${ }^{*} p \llbracket 0.05$ is considered statistically.

Table4 Influencing factors of Hcy in $1^{\text {st }}$ trimester

\begin{tabular}{|c|c|c|c|c|c|c|c|c|}
\hline & \multicolumn{4}{|c|}{ Univariate analysis } & \multicolumn{4}{|c|}{ Multivariate analysis } \\
\hline & Coef $(95 \% C I)$ & $\begin{array}{l}\text { Std. } \\
\text { Error }\end{array}$ & Statistic & $p$ & Estimate (95\%CI) & $\begin{array}{l}\text { Std. } \\
\text { Error }\end{array}$ & $\begin{array}{c}t \\
\text { value/Chisq }\end{array}$ & $p$ \\
\hline Age & $-0.013(-0.029,0.002)$ & 0.008 & -1.697 & 0.090 & & & & \\
\hline $\begin{array}{l}\text { History of spontaneous } \\
\text { abortion }\end{array}$ & $-0.123(-0.3,0.054)$ & 0.090 & -1.365 & 0.173 & & & & \\
\hline History of PE & $1.406(0.218,2.594)$ & 0.606 & 2.320 & 0.021 & $1.402(0.326 \square 2.478)$ & 0.548 & 2.556 & 0.011 \\
\hline History of FGR & $-2.166(-4.223,-0.11)$ & 1.049 & -2.064 & 0.039 & & & & \\
\hline Creatinine $^{*}$ & $0.043(0.033,0.053)$ & 0.005 & 8.806 & $<0.001$ & $0.040(0.030 \square 0.049)$ & 0.005 & 8.270 & $<0.001$ \\
\hline Albumin* & $0.103(0.075,0.131)$ & 0.014 & 7.309 & $<0.001$ & $0.093(0.067,0.118)$ & 0.013 & 7.026 & $<0.001$ \\
\hline Globulin* & $0.019(-0.001,0.039)$ & 0.010 & 1.901 & 0.058 & $0.031(0.012,0.049)$ & 0.009 & 3.265 & 0.001 \\
\hline Total cholesterol & $-0.108(-0.192,-0.024)$ & 0.043 & -2.516 & 0.012 & & & & \\
\hline HDL & $-0.024(-0.182,0.135)$ & 0.081 & -0.292 & 0.770 & & & & \\
\hline LDL $^{*}$ & $-0.135(-0.233,-0.036)$ & 0.050 & -2.685 & 0.007 & $-0.116(-0.211,-0.022)$ & 0.048 & -2.408 & 0.016 \\
\hline \multicolumn{9}{|l|}{ MTHFR } \\
\hline rs1801133* & & & 23.500 & 0.000 & & & 18.242 & $<0.001$ \\
\hline $\mathrm{CT}^{*}$ & $0.163(0.024,0.301)$ & 0.071 & 2.299 & 0.022 & $0.147(0.018,0.275)$ & 0.065 & 2.241 & 0.025 \\
\hline $\mathrm{TT}^{*}$ & $0.417(0.249,0.585)$ & 0.086 & 4.869 & $<0.001$ & $0.343(0.185,0.501)$ & 0.081 & 4.257 & $<0.001$ \\
\hline rs1801131 & & & 16.300 & $<0.001$ & & & & \\
\hline $\mathrm{AC}$ & $-0.178(-0.309,-0.046)$ & 0.067 & -2.648 & 0.008 & & & & \\
\hline $\mathrm{CC}$ & $-0.614(-0.973,-0.256)$ & 0.183 & -3.357 & 0.001 & & & & \\
\hline rs17367504* & & & 29.100 & $<0.001$ & & & 21.418 & $<0.001$ \\
\hline $\mathrm{AG}^{*}$ & $-0.389(-0.554,-0.225)$ & 0.084 & -4.647 & $<0.001$ & $-0.311(-0.464,-0.157)$ & 0.078 & -3.970 & $<0.001$ \\
\hline $\mathrm{GG}^{*}$ & $-1.035(-1.716,-0.353)$ & 0.348 & -2.977 & 0.003 & $-0.832(-1.459,-0.205)$ & 0.320 & -2.602 & 0.009 \\
\hline Intercept & & & & & $-4.390(-6.335 \square-2.446)$ & 0.991 & -4.430 & $<0.001$ \\
\hline
\end{tabular}

${ }^{*} p \llbracket 0.05$ is considered statistically. 
Table5 Univariate and multivariate Logistic regression models were used to analyze the influencing factors of preeclampsia

\begin{tabular}{|c|c|c|c|c|c|c|c|c|c|c|}
\hline & & & Univ & ariate analysis & & & & Multivaria & te analys & \\
\hline & Estimate & $\begin{array}{l}\text { Std. } \\
\text { Error }\end{array}$ & statistic & OR(95\%CI) & $p$ & Estimate & $\begin{array}{l}\text { Std. } \\
\text { Error }\end{array}$ & $\begin{array}{c}z \\
\text { value/Chiq }\end{array}$ & $p$ & $\begin{array}{c}\text { OR } \\
(95 \% C I)\end{array}$ \\
\hline MTHFR & & & & & & & & & & \\
\hline rs1801133 & & & 0.518 & & 0.772 & & & & & \\
\hline CT & 0.275 & 0.418 & 0.659 & $1.317(0.5935,3.1228)$ & 0.510 & & & & & \\
\hline $\mathrm{TT}$ & 0.283 & 0.493 & 0.575 & $1.328(0.4921,3.52)$ & 0.565 & & & & & \\
\hline rs1801131 & & & 5.831 & & 0.054 & & & 4.357 & 0.113 & \\
\hline AC & -0.814 & 0.455 & -1.790 & $0.443(0.1646,1.0098)$ & 0.073 & -0.646 & 0.470 & -1.374 & 0.170 & $\begin{array}{c}0.44 \\
(0.18,1.08)\end{array}$ \\
\hline $\mathrm{CC}$ & -14.313 & 678.479 & -0.021 & $0(0,306789783.661)$ & 0.983 & -15.210 & 1032.000 & -0.015 & 0.988 & $0(0$, Inf $)$ \\
\hline rs17367504 & & & 1.086 & & 0.581 & & & & & \\
\hline AG & -0.378 & 0.539 & -0.702 & $0.685(0.2017,1.7625)$ & 0.483 & & & & & \\
\hline GG & -13.143 & 799.848 & -0.016 & 0 (NA,1.70282464513331e+22) & 0.987 & & & & & \\
\hline $\begin{array}{l}1^{\text {st }} \\
\text { trimester }\end{array}$ & & & & & & & & & & \\
\hline Hcy & -0.082 & 0.172 & -0.478 & $0.921(0.6496,1.2689)$ & 0.632 & & & & & \\
\hline $\begin{array}{l}\text { Folic } \\
\text { acid }\end{array}$ & -0.037 & 0.023 & -1.592 & $0.964(0.9232,1.0101)$ & 0.111 & & & & & \\
\hline Vit B12 & -0.001 & 0.001 & -0.830 & $0.999(0.9962,1.0012)$ & 0.407 & & & & & \\
\hline $\begin{array}{l}2^{\text {nd }} \\
\text { trimester }\end{array}$ & & & & & & & & & & \\
\hline Нсy & -0.176 & 0.136 & -1.295 & $0.839(0.6336,1.0772)$ & 0.195 & & & & & \\
\hline $\begin{array}{l}\text { Folic } \\
\text { acid }\end{array}$ & -0.012 & 0.014 & -0.903 & $0.988(0.9602,1.0135)$ & 0.367 & & & & & \\
\hline Vit B12 & -0.002 & 0.002 & -0.995 & $0.998(0.9945,1.0012)$ & 0.320 & & & & & \\
\hline $\begin{array}{l}3^{\text {rd }} \\
\text { trimester }\end{array}$ & & & & & & & & & & \\
\hline Hсy & 0.150 & 0.076 & 1.976 & $1.162(0.9862,1.335)$ & 0.048 & 0.179 & 0.088 & 2.038 & 0.042 & $\begin{array}{c}1.16 \\
(1,1.35)\end{array}$ \\
\hline $\begin{array}{l}\text { Folic } \\
\text { acid }\end{array}$ & 0.007 & 0.010 & 0.662 & $1.007(0.9858,1.0249)$ & 0.508 & & & & & \\
\hline Vit B12 & 0.000 & 0.002 & -0.228 & $1(0.9958,1.002)$ & 0.820 & & & & & \\
\hline Intercept & & & & & & -18.830 & 3.932 & -4.789 & $<0.001$ & \\
\hline
\end{tabular}

${ }^{*} p \llbracket 0.05$ is considered statistically.

\section{Figures}

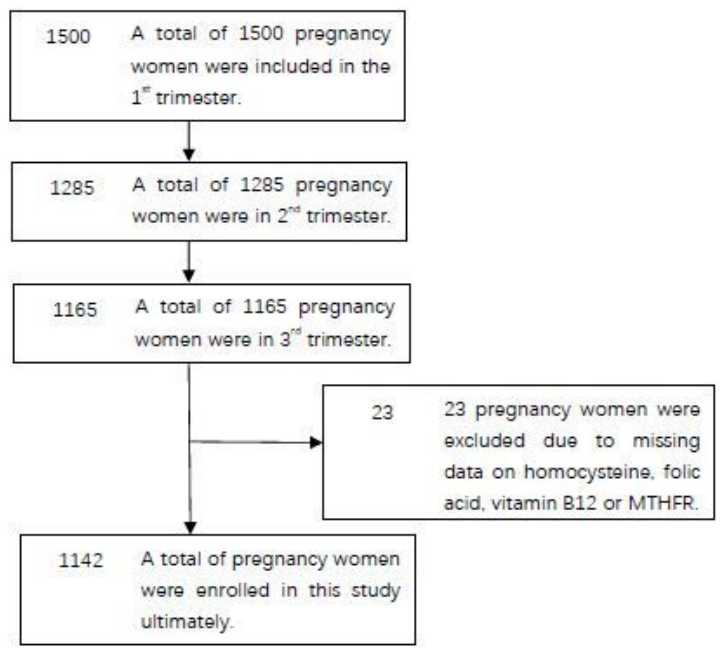

Figure 1

Selection of study participants 


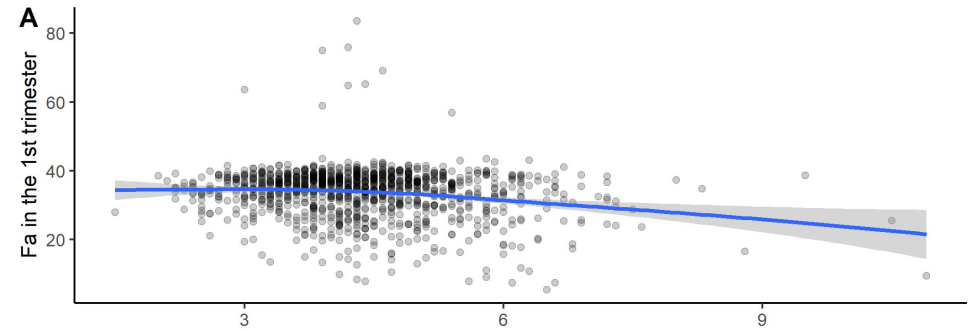

Hcy in the 1st trimester
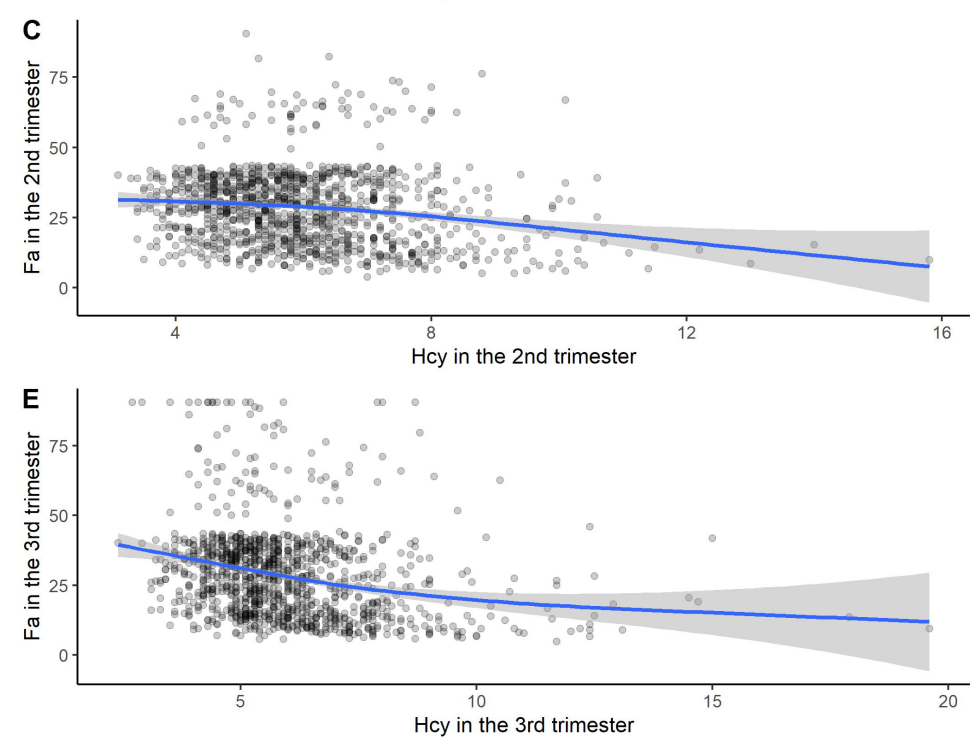

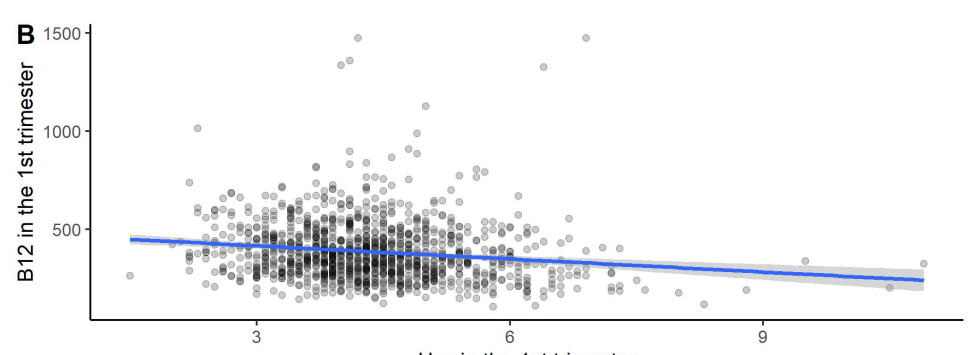

Hcy in the 1 st trimester
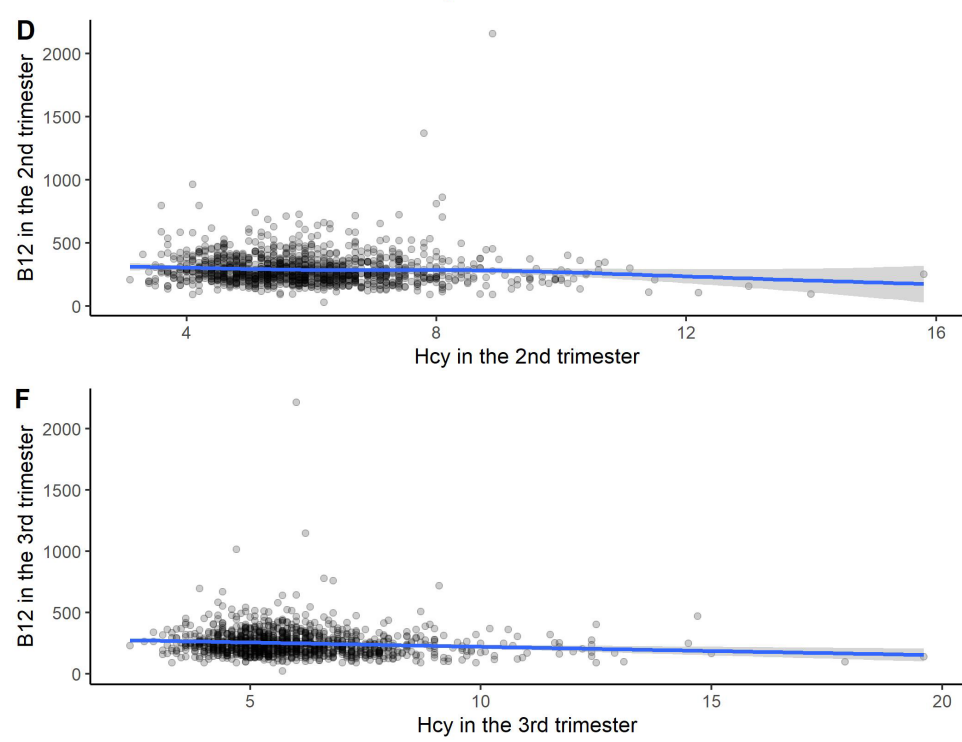

\section{Figure 2}

Hcy, FA and B12 levels at different stages of pregnancy (A) Hcy levels at three stages of pregnancy;(B) FA levels at three stages of pregnancy;(C) B12 levels at three stages of pregnancy.
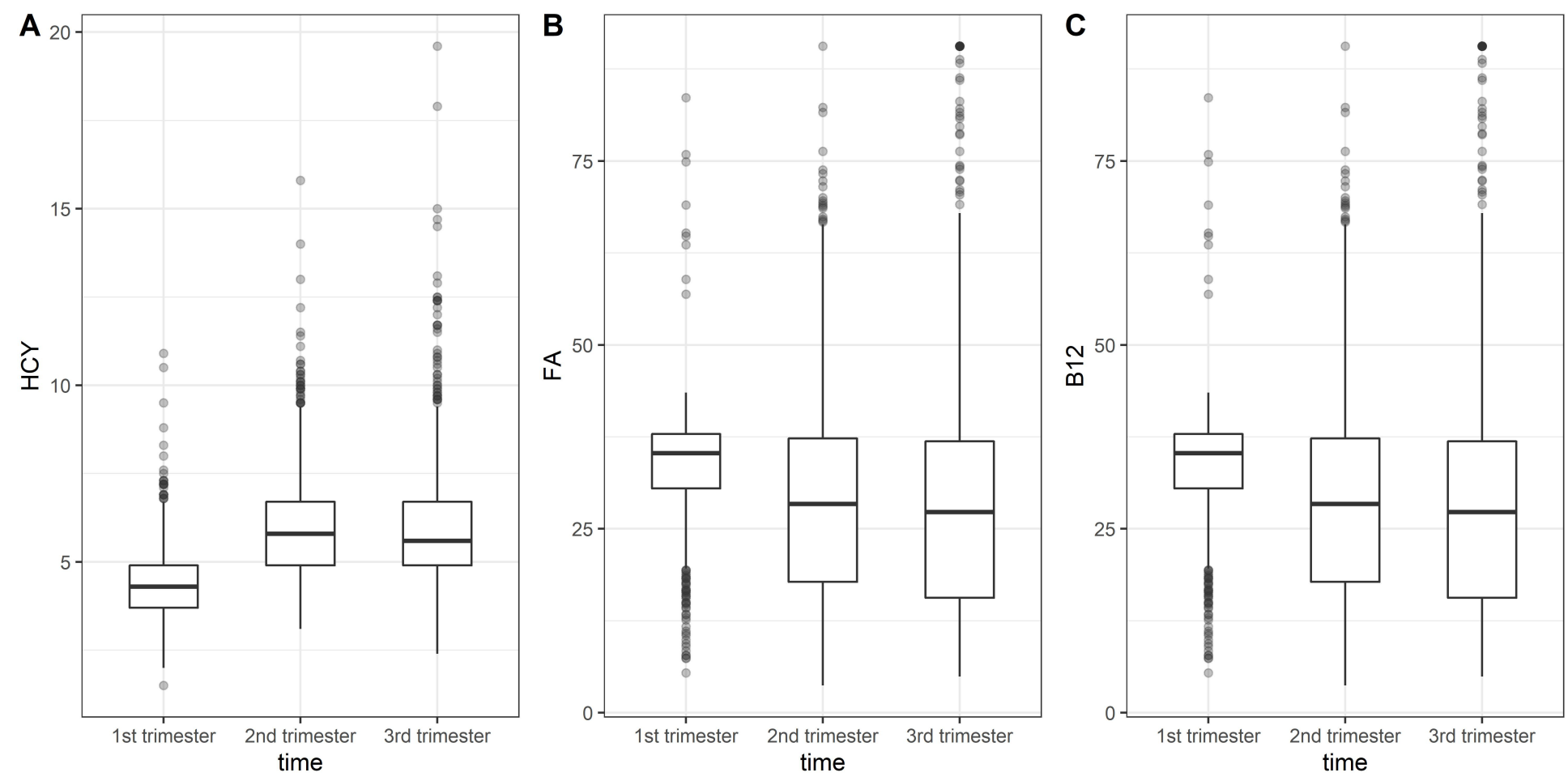

Figure 3

Scatter diagram of Hcy, FA and Vit B12 (A) FA and Hcy were negatively correlated in the 1st trimester. (B) Vitamin B12 and Hcy were negatively correlated in the 1st trimester. (C) FA and Hcy were negatively correlated in the 2nd trimester. (D) Vitamin B12 and Hcy were negatively correlated in the 2nd trimester. (E) FA and Hcy were negatively correlated in the 3rd trimester. (F) Vitamin B12 and Hcy were negatively correlated in the 3rd trimester. 